Por volta dos anos 80, como Presidente da Sociedade Paulista de Ortodontia, tive a oportunidade de conhecer o professor Hugo J. Trevisi e vislumbrar as qualidades inatas de liderança, criatividade, dedicação, de trabalho contínuo na busca da excelência em Ortodontia. Naquele tempo, o professor Trevisi já formava dupla com o professor McLaughlin, tendo este último ministrado um curso na cidade de Presidente Prudente à convite do primeiro. Feliz acontecimento, pois a partir desse evento surgiu uma união profissional que originou uma experiência ortodôntica ímpar para o desenvolvimento da Ortodontia brasileira e internacional. Podemos afirmar que o professor Hugo J. Trevisi é um dos principais, ou senão o principal responsável pela introdução e desenvolvimento da técnica ortodôntica com aparelhos préajustados no Brasil. Nas décadas de 80 e 90, o professor Trevisi coordenou inúmeros cursos para brasileiros, nos Estados Unidos, enfocando a técnica Straight Wire, divulgando e preparando, nesse campo, muitos professores patrícios. Dessa maneira, a técnica com aparelhos pré-ajustados teve condições de desenvolver-se, no Brasil, de maneira significativa.

A trajetória de vida profissional do professor Trevisi, com certeza, foi pautada por sacrifícios pessoais, dedicação contínua e desprendimento, os quais são fatores fundamentais para o sucesso pessoal e, principalmente, para a contribuição científica decorrente, em prol das coletividades, brasileira e internacional, no campo ortodôntico.

O emérito professor ministra, de maneira incansável, cursos por todas as regiões deste planeta, divulgando os seus conhecimentos e demonstrando a presença brasileira na estrutura de uma filosofia de tratamento internacional (Filosofia de tratamento MBT), engrandecendo a Ortodontia, como ciência, de uma maneira insofismável.

O professor Trevisi fundou um centro de estudos ortodônticos (referência no Brasil), na cidade de Presidente Prudente, coordena um curso de especialização na regional da $A P C D$ e desenvolve trabalhos importantes na área especifica.

A técnica Ortodôntica Versátil MBT e o Aparelho Autoligado SmartClip foram idealizados pelos professores J. Bennett, Richard McLaughlin e Hugo Trevisi. Esta tecnologia, que dá sustentação à filosofia de tratamento MBT, é de importância capital para a formação dos ortodontistas, uma vez que os autores conseguiram facilitar o trabalho de correção das más oclusões dentárias, produzindo uma biomecânica compativel com os níveis científicos atualizados e com possibilidades de alcance das metas ideais de tratamento.

Este fato e o trabalho dos autores supra-citados, por si só, recomendam o nome do professor Trevisi como um dos profissionais de relevo dentro da ciência de Angle. Estamos apresentando, formalmente, nesta entrevista, um digno e ilustre companheiro das lides ortodônticas neste Brasil, que a nosso ver, representa uma personalidade marcante na história da Ortodontia brasileira.

Prof. Dr. Julio Wilson Vigorito

\section{Hugo J. Trevisi}

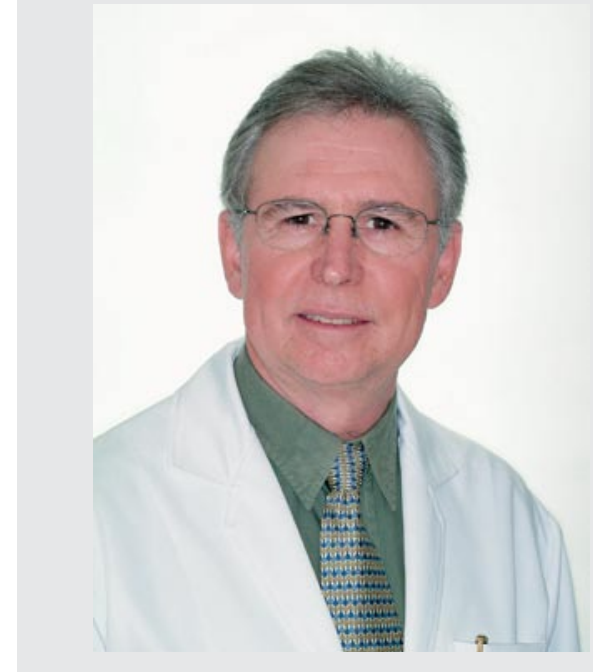

Dr. Hugo J. Trevisi recebeu sua formação ortodôntica na Faculdade de Odontologia de Lins/SP, em 1979. Desde então, dedica-se à prática ortodôntica em Presidente Prudente, Brasil. Dr. Trevisi é coordenador do curso de Especialização em Ortodontia da APCD - Regional de Presidente Prudente, é Professor do Curso de Especialização em Ortodontia da $A B C D / M T$, Coordenador do Curso de Especialização em Ortodontia da Universidad del Desarrollo no Chile e ministra vários cursos na América do Sul, América Central, EUA, Canadá, Europa, Ásia e Emirados Árabes. Dr. Trevisi tem mais de vinte e cinco anos de experiência com os aparelhos pré-ajustados e tem seu próprio centro de estudos ortodônticos em Presidente Prudente/SP. Juntamente com os doutores Bennett e McLaughlin, Dr. Trevisi é o idealizador da Técnica Ortodôntica Versátil MBT e um dos idealizadores do Aparelho Autoligado SmartClip.

Neste momento de glória desta renomada revista, que completa 10 anos de existência, quero agradecer a oportunidade de, mais uma vez, fazer parte de uma matéria de publicação e, também, quero agradecer aos profissionais que formularam as perguntas por mim respondidas. Nesta oportunidade, espero ter esclarecido tópicos importantes da prática diária dos profissionais, ajudando no engrandecimento da Ortodontia brasileira - Hugo Trevisi.

\section{1) Por ser o senhor um grande conhece- dor da Ortodontia praticada em quase todo - mundo, gostaria que situasse a Ortodontia nacional, considerando os aspectos técnicos, científicos e econômicos, quando comparada à de outros países? Reginaldo C. Zanelato}

A partir da década de 1980, momento em que se deu a introdução dos aparelhos pré-ajustados, a Ortodontia brasileira evoluiu muito, passando a ser uma das melhores praticadas no mundo, considerando-se o aspecto técnico e científico. Infelizmente, nos últimos anos, a ciência ortodôntica em nosso país vem decaindo, devido às dificuldades econômicas que estamos vivendo. Tal fato não é positivo, pois quando há empobrecimento, passamos a não nos enquadrarmos mais no contexto mundial e a sermos carentes de novas informações relacionadas à ciência e à tecnologia. 
2) Após quase dez anos da introdução da prescrição de braquetes MBT, o senhor vê a necessidade de se fazer algum ajuste na prescrição dos braquetes MBT? Reginaldo C. Zanelato

Técnicas ortodônticas que não evoluíram o suficiente foram substituídas por idéias melhores. O sistema MBT tem passado por aprimoramento constante, considerando-se a tecnologia, a biomecânica e a prescrição. Tais inovações são necessárias, devido ao avanço tecnológico mundial.

3) A Ortodontia atual está passando por grandes modificações, principalmente com a utilização dos aparelhos autoligados. Qual a sua expectativa quanto à utilização destes braquetes na prática dos ortodontistas e quanto tempo levará para esses braquetes serem usados como rotina nos consultórios de Ortodontia? Reginaldo C. Zanelato

Associarei esta pergunta à pergunta número 1 . Os aparelhos autoligados são os que mais vêm crescendo no mundo desde o ano de 2002. Em vários países, a porcentagem de uso de aparelhos autoligados, quando comparada à de aparelhos ligados, é bastante grande. No Brasil, infelizmente, não estamos acompanhando este crescimento, devido às dificuldades econômicas que estamos vivendo. Em minha opinião, num contexto global, em poucos anos a Ortodontia praticada com aparelhos autoligados será bastante grande, quando comparada aos aparelhos ligados.

4) Como o senhor é um grande formador de opinião, e pessoas assim tem grande responsabilidade no preparo de novos profissionais, gostaria de saber qual o conselho que 0 senhor daria à nova geração de ortodontistas brasileiros. Reginaldo C. Zanelato

O conselho que dou à nova geração de profissionais é que tenham formação profissional com embasamento científico, enfocando o conhecimento prático de técnicas ortodônticas reconhecidas internacionalmente.
5) O aparelho MBT tem tido boa aceitação mundial entre os ortodontistas? Flávio Vellini

$\mathrm{O}$ aparelho MBT ultrapassou nossas expectativas de aceitação mundial, que é crescente e sustentável. O aparelho MBT é o aparelho mais jovem no mercado mundial e já é um dos mais utilizados pelos ortodontistas de todo o mundo.

6) Quais os pontos positivos apresentados por este tipo de aparelho em relação aos similares que utilizam 0 arco contínuo? Flávio Vellini

Melhor controle de torque, diminuição das angulações no sistema de braquetes e uso de nova tecnologia foram pontos positivos do sistema MBT, quando comparado às demais técnicas. Há, agora, tubos rebaixados para pré-molares e molares inferiores. Tais aprimoramentos na técnica favorecem o posicionamento do aparelho, facilitando o gerenciamento das biomecânicas e a fase de detalhes e acabamento no final do tratamento ortodôntico.

7) Qual o mais marcante avanço no desenho do aparelho MBT nestes últimos anos? Flávio Vellini

Nosúltimos anos, o avanço mais marcante no desenho do aparelho MBT relaciona-se aos tubos bucais dos pré-molares e molares, aos braquetes com perfil baixo e ao aparelho autoligado SmartClip. Com tubos rebaixados, ganham-se $2 \mathrm{~mm}$ extras no sentido vertical, devido à eliminação das aletas oclusais. Tal fato favorece o posicionamento dos braquetes, eliminando as interferências oclusais dos dentes superiores com os dentes inferiores, nos casos de sobremordidas profundas, diminuindo, assim, a queda de braquetes inferiores.

8) Podemos dizer que vislumbramos um futuro cada vez mais promissor para 0 aparelho MBT? Flávio Vellini

A filosofia de tratamento ortodôntico MBT é dinâmica, estando em constante inovação. Tal fato faz com que os profissionais que praticam a técnica estejam constantemente atualizados, recebendo novas informações científicas através de livros, 
artigos e lançamentos de novos produtos. Para exemplificar, estaremos lançando, em alguns meses, um livro sobre o aparelho autoligado SmartClip.

9) Caro Prof. Trevisi, temos observado um grande crescimento da filosofia de tratamento ortodôntico MBT pelo Brasil e por todos os continentes do mundo. Um dos motivos desta grande aceitação é devido ao fato da filosofia MBT ser muito dinâmica e atualizarse constantemente. Quais as inovações mais recentes em relação à prescrição e à biomecânica utilizada na filosofia MBT? Ricardo Moresca

O sistema MBT não surgiu somente como uma técnica ortodôntica, mas sim como uma filosofia de tratamento ortodôntico com objetivos claros de diagnóstico, planejamento e biomecânica. Novas idéias são constantemente agregadas à filosofia, o que faz com que a mesma tenha crescimento sustentável. Considerando-se a prescrição de braquetes, introduzimos dois braquetes adicionais, ou seja, braquete de segundo molar superior com $-19^{\circ}$ de torque e braquete de incisivo central com $22^{\circ}$ de torque. Estes braquetes facilitam o controle de torque nas biomecânicas de várias más oclusões.

10) O Sr. foi o principal responsável pelo desenvolvimento dos braquetes autoligados SmartClip. Quais as principais diferenças em relação aos demais braquetes autoligados e as principais vantagens que este sistema de braquetes proporciona ao tratamento ortodôntico? Ricardo Moresca

Em minha opinião, os aparelhos autoligados são o futuro da Ortodontia. O aparelho autoligado SmartClip foi desenvolvido com o objetivo de diminuir a friç̧ão existente entre o fio e a canaleta dos braquetes. Com a diminuição da fricção na execução das biomecânicas ortodônticas, diminuiem-se os níveis de força. Com a aplicação de forças mais biológicas, eliminam-se as resultantes no tratamento ortodôntico. As resultantes impedem a perfeita execução da biomecânica de deslize. Tal fato aumenta o tempo de tratamento ortodôntico. Adicionalmente, o aparelho autoligado SmartClip favorece a saúde periodontal do paciente.

11) Durante o encontro mundial do grupo de estudo sobre a filosofia MBT, que aconteceu em Las Vegas em maio passado, o Sr. apresentou vários casos tratados com os braquetes SmartClip. Em relação aos tratamentos com extrações, o que muda com a utilização destes braquetes? Ricardo Moresca

O uso do aparelho autoligado SmartClip em casos de extração de pré-molares apresenta performance excelente, pois não há fricção clássica. Com a ausência da friç̧ão clássica, diminuiem-se os níveis de força e há o favorecimento da biomecânica aplicada, diminuindo o tempo de tratamento ortodôntico.

12) O Senhor é reconhecido como uns dos ortodontistas mais habilidosos do Brasil. Que conselhos o Sr. daria para os ortodontistas que desejam atingir o seu nível de finalização do tratamento ortodôntico? Ricardo Moresca

Independentemente do diagnóstico e do plano de tratamento, para finalizar um tratamento ortodôntico com êxito é importante saber que a Ortodontia aplicada no paciente faz-se com braquetes e tubos bucais em igual importância, sendo primordial que o ortodontista atenha-se a dois fatores básicos:

1) Utilizar técnicas ortodônticas que apresentem bons recursos técnicos e científicos.

2) Esmerar-se no posicionamento de braquetes, utilizando a técnica de posicionamento individualizado de braquetes.

13) Sabemos que o Sr. foi o introdutor da filosofia dos aparelhos ortodônticos pré-ajustados no Brasil. Como se deu o processo de introdução da filosofia no Brasil? Quem foi o seu contato nos EUA? Adriano C. Zanelato

$\mathrm{Na}$ década de 1980, a introdução dos aparelhos pré-ajustados no Brasil foi bastante difícil, 
devido à rejeição a novas tecnologias. Com o passar do tempo, a aceitação a esta nova idéia foi crescendo e, atualmente, mais de 95\% da Ortodontia praticada no Brasil e no mundo faz-se com aparelhos pré-ajustados.

14) Quais eram as dificuldades de trabaIho que o Sr. tinha com os aparelhos ortodônticos pré-ajustados antes do desenvolvimento da filosofia MBT? O que o motivou a desenvolver uma nova filosofia para aparelhos ortodônticos pré-ajustados? Adriano C. Zanelato

Hoje podemos fazer um bom diagnóstico sobre os problemas que tivemos no passado quando da introdução dos primeiros aparelhos pré-ajustados (Straight-Wire).

Os problemas principais apresentados pelos primeiros aparelhos pré-ajustados relacionavamse ao excesso de angulação dos dentes anteriores superiores e inferiores, à ausência de torque no segmento anterior superior, ao excesso de torque negativo no segmento inferior posterior, à ausência de torque negativo do segmento superior posterior e ao sistema de posicionamento de braquetes. Todos os fatores mencionados acima foram motivos suficientes para lançar uma nova filosofia de aparelhos ortodônticos, contendo características que favoreceriam a biomecânica de tratamento, minimizando os problemas apresentado pelos aparelhos previamente desenvolvidos.

15) Sabe-se que o senhor tem trabalhado muito no desenvolvimento do aparelho autoligado SmartClip, sendo este um aparelho de última geração. Como o senhor avalia a mecânica ortodôntica dos aparelhos ligados, comparando-as aos aparelhos autoligados? Adriano C. Zanelato

Os aparelhos pré-ajustados, independentemente da técnica utilizada, apresentam alto nível de fricção clássica, dificultando a execução das biomecânicas ortodônticas. O aparelho SmartClip elimina esta fricção, favorecendo a diminuição dos níveis de força aplicados nas três fases do trata- mento (alinhamento, nivelamento e fechamento de espaços). Baixando os níveis de força, o ortodontista tem melhor controle da biomecânica e da finalização dos tratamentos.

16) Você foi o pioneiro do Straight-Wire no Brasil. Hoje você adota a filosofia MBT. Quais foram as mudanças desde o início até agora com o MBT? Jurandir A. Barbosa

Desde a introdução do primeiro aparelho Straight-Wire, muitas foram as mudanças ocorridas. Na década de 1970, a idéia de Andrews de introduzir um aparelho pré-ajustado foi fantástica. Atualmente, todo o mundo utiliza aparelhos pré-ajustados, mas não o primeiro aparelho idealizado. Tal fato significa que o primeiro aparelho Straigth-Wire desenvolvido necessitou de ajustes relacionados aos torques, angulações, rotações e design. Com Roth, introduziram-se algumas mudanças, seguindo-se, posteriormente, a maturação do processo. Considerando-se a filosofia MBT, durante sua criação definiu-se primeiramente a biomecânica de deslize que melhor trabalharia com esses aparelhos, utilizando fio 0,019 " x 0,025 " como o de calibre final. E, somente após a consideração e definição destes fatos é que se definiu o aparelho. O aparelho MBT ajustou o controle de torque para dentes anteriores, introduziu mais torque positivo para incisivos superiores, mais torque negativo para incisivos inferiores, reduziu as angulações para dentes anteriores superiores e inferiores, estabeleceu três possibilidades de torque para caninos superiores e inferiores, aumentou os torques negativos para os molares superiores e reduziu progressivamente os torques de primeiro pré-molar a segundo molar inferior.

17) Como você tem atuado para controlar a fricção entre fio e braquete, que é comum no Straight-Wire tradicional? Jurandir A. Barbosa

Atualmente, fricção é o assunto mais discutido em Ortodontia em todo o mundo. Tal fato deve ser relevante a todos os profissionais. $\mathrm{Na}$ execução das biomecânicas ortodônticas, utilizando aparelhos ligados, fazem-se presentes três tipos 
de atrito: atrito clássico, atrito binding e atrito notching. Os dois últimos atritos são bastante difíceis de controlar na execução das biomecânicas. $\mathrm{O}$ atrito clássico ocorre devido às amarras que utilizamos para fixar o arco nos braquetes. O ortodontista tem de usar artifícios criativos no aparelho ligado para eliminar este atrito, pois a mesma faz-se presente em todas as fases do tratamento. Atualmente, tubos bucais de segundos pré-molares associados a tubos especiais de molares são uma boa opção na fase de fechamento de espaços.

18) Sei da sua experiência com relação a exodontias de segundos molares como opção de tratamento. Gostaria que você justificasse quando devemos lançar mão deste recurso. Jurandir A. Barbosa

A exodontia de segundos molares é uma boa opção de tratamento para determinadas más oclusões. As opções de tratamento para se fazer uso de extrações de segundos molares são:

- Más oclusões de Classe II, extraindo-se os segundos molares superiores.

- Más oclusões de Classe III com pequena mordida aberta, extraindo-se os segundos molares inferiores.

- Más oclusões de Classe I com pequena mordida aberta, extraindo-se os quatros segundos molares.

Quaisquer que sejam as opções utilizadas, devese considerar a idade ideal do paciente, que deve ser de 12 a 15 anos idade, momento em que se inicia a formação radicular dos terceiros molares, com forma e tamanho de coroa bem definidas.

19) $O$ "efeito montanha russa" é um efeito colateral do Straight-Wire tradicional e, em algum momento, foi dito no livro do Dr. McLaughlin que era provocado pelo uso de forças pesadas. Qual sua opinião sobre este efeito? Jurandir A. Barbosa

Em minha opinião, o "efeito montanha-russa" causado nas biomecânicas ortodônticas relacionase a três fatores:

1) Excesso de força aplicada nas biomecânicas ortodônticas.
2) Excesso de angulação dos braquetes dos dentes anteriores.

3) Posicionamento de braquetes utilizando o eixo vestibular das coroas clínicas como referência.

Adriano Cesar Trevisi Zanelato

- Especialista em Ortodontia - ABO-MS;

- Mestre em Ortodontia pela UMESP - São Bernardo do Campo (SP);

- Professor do Curso de Especialização em Ortodontia APCD de Presidente Prudente (SP);

- Professor do Curso de Especialização em Ortodontia - ABCD de Cuiabá (MT).

Flávio Vellini-Ferreira

- Doutor, Livre-Docente e Professor Associado pela USP;

- Coordenador do Curso de Mestrado em Ortodontia da Universidade Cidade de São Paulo - UNICID

- Diretor do Centro de Treinamento Odontológico e Coordenador dos Cursos de Pós Graduação em Ortodontia do Instituto Prof. Flávio Vellini;

- Member of the MBT Global Group

- Autor do Livro ORTODONTIA - Diagnóstico e Planejamento Clínico Ed. Artes Médicas $6^{\mathrm{a}}$ Edição e $2^{\mathrm{a}}$ Edição em Espanhol.

Jurandir A. Barbosa

- Mestre em Ortodontia pela USP-Bauru;

- Professor coordenador do curso de especialização em Ortodontia da A.C.D.C - Campinas;

- Professor na S.L.Mandic - Campinas:

- Presidente do Grupo Straight Wire - Brasil.

Reginaldo C. Zanelato

- Especialista e Mestre em Ortodontia

- Professor do Curso de Especialização de Ortodontia da APCD de Presidente Prudente;

- Professor do Curso de Especialização de Ortodontia da ABCD de Cuiabá;

- Professor do Curso de Pós-graduação de Ortodontia da Universidad del Desarrollo de Concepción - Chile;

- Coordenador do Curso de Especialização de Ortodontia da INAPÓS de Presidente Prudente.

\section{Ricardo Moresca}

- Especialista em Ortodontia - UFPR;

- Mestre em Ortodontia - UMESP

- Doutor em Ortodontia - FOUSP

- Professor do Departamento de Anatomia da UFPR;

- Professor da Disciplina de Ortodontia Preventiva e do Curso de Especialização em Ortodontia da UFPR;

- Professor da Disciplina da Odontologia da Infância e da Adolescência e do Curso de Especialização em Ortodontia da UFPR;

- Professor do Curso de Especialização em Ortodontia da ABO - Guarapuava;

- Secretário Geral da Associação Paranaense de Ortodontia. 